\title{
Beyond the bench: A conversation with Tonya White
}

\section{BY ANGIE VOYLES ASKHAM}

29 JUNE 2021

Tonya White likes to move.

She has switched academic disciplines several times, moving across an ocean in the wake of one career shift. After earning her M.S. in electrical engineering at the University of Illinois, she changed gears and went into medicine. Fifteen years later, she was a child psychiatrist at the University of Minnesota when she decided to go back to engineering - the biomedical kind this time - and re-entered graduate school. And in the middle of that Ph.D. program, she relocated to the Netherlands to set up a neuroimaging program at Erasmus University in Rotterdam, where she still works.

Her lifestyle mirrors her dynamic career path. She cross-country skis in the winter and sails when she can get her hands on a boat. In the middle of the pandemic, she took a nearly 1,000-mile 'bikepacking' trip across eight countries. And after more sitting than usual this past year left her with back pain, she has added walks, bike rides and as many al fresco meetings as possible to her day.

As associate professor of child and adolescent psychiatry, White, now in her 50 s, studies how the womb and early life experiences shape brain development and contribute to conditions such as autism. She spoke with Spectrum about the routines she hopes to hold onto post-COVID-19, the art she created from crushed seashells and how her father instilled her love of science.

\section{Spectrum: When did you first become interested in science?}

Tonya White: My parents started me out. When I was 8 or 9 years old, my father would order these little blue kits once a month for me. Each would be a science project - experiments with electricity and things you would mix together to make different chemical substances. I thought those were really cool. Like solving puzzles. 


\section{Spectrum | Autism Research News}

https://staging.spectrumnews.org

\section{S: What 'big question' drives your research?}

TW: I'm very interested in the whole [autism] spectrum and its neurobiological underpinnings. John Constantino and others would say this spectrum extends to the entire population - that there's a certain population distribution of the traits of autism: Some people have some autism traits, others have more and still others have a lot.

And so the question is, does the underlying neurobiology parallel the traits? Do you see a spectrum in the neurobiology similar to the spectrum you see in the behavioral phenotype? And if so, what does that mean about how the combination of different genetic effects shapes a person's likelihood of being autistic?

The other possibility is that the underlying neurobiology does not fall along a spectrum, even if the behavior does. You don't have any changes in the brain up to a certain genetic load. And it's at that point that the behavioral traits are evident.

\section{S: Whose work do you admire?}

TW: I really admire Chuck Nelson's creativity, his vision to focus on the effects of deprivation on child development. I also admire how Nancy Andreasen thinks about the brain - her multifactorial approach to studying the brain networks related to schizophrenia. And I admire how Irv Gottesman thought about research. And how, as a mentor, he could bring life and relevance to the things I was reading in the literature.

Child psychiatrist Judy Rapoport at the National Institutes of Health has done phenomenal work on child-onset schizophrenia. She showed that it had very much the same characteristics, in terms of the brain differences, as what you see in adults. It was just worse. She studied how these differences develop longitudinally — so, what do you see as the individuals grow older?

Some other work I found really fascinating came from the late Klaus Gärtner, an animal scientist at the Hannover Medical School in Germany. He was trying to standardize laboratory animals - to breed animals that are genetically identical, and then see if, by tightly controlling their environment, they end up essentially the same. And then, could you see the effect of environmental changes on different systems, including the brain? For example, what is the effect of low vitamin D?

And he wrote an interesting paper published back in 1990 that I think everyone should read, that essentially says that after 30 years of research he was unsuccessful: Even though the animals were genetically identical and had the same environments, they had different-sized organs. So something else very early in gestation was contributing to that variability. That influenced me in terms of trying to understand that there is a level of individual variability as a result of stochastic, or unpredictable, events in development. 


\section{S: What does a day at work look like for you?}

TW: What it has looked like recently, during the pandemic, is that after getting up, I usually go for a walk. When I get back, I have breakfast and watch the news. And then I go through my email and then have many hours of video conference calls with graduate students, or calls that are administrative related, like data-management issues.

Between calls, I try to schedule time to do stretches. And when I need to work on a manuscript or do data analysis, I block out time for that. We haven't started our next wave of brain imaging because of COVID-19. We're getting ready to start it up now.

And then, generally, after work l'll go for a bike ride before coming back and having dinner.

Pandemic pose: Despite her love of cycling, Tonya White sat in her home office a lot over the past year, a habit she blames for her back pain.

\section{S: Where do you like to ride?}

TW: I have a number of routes, often selected to avoid stoplights. I have a 15-kilometer (9-mile) loop, a 30-kilometer (19-mile) loop and a 73-kilometer (45-mile) loop, which I do only on the weekends. On the weekends, sometimes I'll skip the loop and go exploring.

\section{S: When and where are you most productive?}

TW: If I'm writing grants or focusing on something, I work best at home, where there are few interruptions. I go into hibernation, so to speak.

For meetings, I like to be at work. I like to walk to meetings, and I walk during meetings with my Ph.D. students and postdocs. There's a particular walking route I take with one of my students. It's along the 'Brandgrenns,' or 'fire border' — the edge of town where Rotterdam was bombed at the beginning of the Second World War.

As we talk about research, we look at history. We see the old buildings on one side of the street, the ones that survived the bombing, and on the other side, the buildings built following the bombing in May of 1940. I think I'll continue this way of meeting when the pandemic is over - the movement and walking and being able to talk about research.

\section{S: Do you listen to music or podcasts while you work?}


TW: If I'm writing, I cannot listen to any music with words. It interferes with my word generation. If I'm doing statistics, working with $\mathrm{R}$ or Python or statistical languages, I can listen to anything. I have this eclectic mix of songs. There's folk music as well as Fleetwood Mac, Goo Goo Dolls, Bob Dylan, The Beatles and The Cranberries.

When I'm slicing vegetables or doing other things, I listen to books on tape. I'm listening to a trilogy by Ken Follett. The first book, "The Pillars of the Earth," I listened to in English. The second one, "World Without End," which I listened to in Dutch, is about a pandemic in the Middle Ages.

\section{S: Are you active on social media?}

TW: Not as much as I should be. I look at my Twitter, what comes in, and I just become overwhelmed. I want a direct plug-in to my brain: A USB port, so I can access all of the useful information instantaneously.

\section{S: How many unread emails are in your inbox right now?}

TW: Twelve. I don't know how many emails I get - more than 100 a day. I check my email multiple times during the day, partly because it's a nice distraction - though sometimes it's not a nice distraction - and partly because I don't want to be intimidated at the end of the day by all the emails that are there.

\section{S: What is the painting on the wall behind you?}

TW: My son painted it. It's a tree, but people often think it's a brain, and I like that. It is kind of brain-like in some ways: the tree structure and the cortical rim here, and white matter going up.

I've decorated my apartment — on an island in the River Maas in Rotterdam — with artwork by other family members, too: watercolors by my mom, and pen-and-ink and acrylic paintings by my other two sons.

And I have a large painting that I did — of a place that I really like in Utah, called Delicate Arch. Over the course of a year, I would bike periodically to Hoek van Holland, a small city on the coast of the North Sea - about a 90-minute ride from Rotterdam - and I would collect different colors of seashells. One winter, I spent about an hour every night crushing the seashells while listening to a book on tape. And I used them to make the painting. I call it "Painting Nature with Nature's Colors."

\section{S: What else do you do for fun?}

TW: The things I do outside of work are generally outside. I love sailing, and I love sailing a small boat. I have a Laser. And when all of the bigger boats are coming in because it's too windy, that's 


\section{Spectrum | Autism Research News}

https://staging.spectrumnews.org

when I like going out, because you can get the centerboard humming, and it's really fun.

I cross-country ski in the winter. And on most Saturdays, regardless of the season, I go rollerskiing with my Nordic club. It's a way to mimic cross-country skiing when there is no snow. I'm also a trainer, and so I often give cross-country ski lessons on Saturday mornings to those who want to try the sport.

And I read, but I don't read books - I listen to them, because I read so much at work that I really just want to be read to.

Cite this article: https://doi.org/10.53053/OZTK2977 